Pediatric

Neurosurgery
Pediatr Neurosurg 2000;32:225

\title{
Pediatric Neurosurgery Should Be Involved in the Activities of the American Academy of Pediatrics
}

The recent formation of the Neurosurgical Section of the American Academy of Pediatrics (AAP) is an example of the efforts of Pediatric Neurosurgery to work closely with and strengthen the relationship with our pediatric colleagues. The AAP has over 55,000 members in the form of primary physicians, pediatric sub-specialists, and surgical sub-specialists. Its role in the care of infant, child and adolescent is not only recognized in the US but throughout the world. The AAP has a continuing interaction with state and federal agencies, legislature and agencies involved in the medical care of children. The AAP has a continuing and long-term program of education, research and enhancement of the scientific knowledge needed for day to day care of diseases of childhood.

Through its Department of Education and Division of Quality Improvement, there is a continuum of activity in the preparation and review of practice parameters, practice guidelines and outcome studies. There are many sections within the AAP, including established surgical sections such as general surgery, orthopedics, plastic surgery, urology, cardiovascular surgery, ENT and ophthalmology. The AAP's Board of Directors response to state and federal government requests, requests from third-party payers and other activities is to foward the necessary information and support on specific subjects and diseases to the various sections within the AAP.
Pediatric Neurosurgery had no section of its own where neurosurgical issues could be triaged and addressed to pediatric neurosurgeons. As a consequence, the 'void' was filled by other sections. As such, position papers and/or statements on craniosynostosis were addressed to the Section of Plastic Surgery. Position papers and/or statements on head injury were addressed to the sections on critical care, emergency medicine and neurology.

If pediatric neurosurgery is to be acknowledged as the source of information and support on neurosurgical issues pertaining to infants, children and adolescents, it is most important to have an administrative venue within the AAP for access to this very vital information. The only true administrative pathway for such a venue is through the establishment of the Section of Neurosurgery within the AAP. In October 1998, we were established as the Provisional Section of Pediatric Neurosurgery. By October 2001, we must demonstrate our commitment to the AAP to become a fully credentialed section. It is, therefore, important that all pediatric neurosurgeons recognize the role of the AAP in the care of children and become active participants in the AAP and the Neurosurgery Section.

Marion L. Walker, MD, FACS, FAAP Salt Lake City, Utah

\begin{tabular}{ll}
\hline KARGER & @ 2000 S. Karger AG, Basel \\
Fax +4161306 1234 & 1016-2291/00/0325-0225\$17.50/0 \\
$\begin{array}{l}\text { E-Mail karger@karger.ch } \\
\text { www.karger.com }\end{array}$ & $\begin{array}{l}\text { Accessible online at: } \\
\text { www.karger.com/journals/pne }\end{array}$
\end{tabular}

